\author{
Klaudiusz Nadolny ${ }^{1,2}$, Jerzy Robert Ładny ${ }^{3}$, Robert Gałązkowski ${ }^{4}$, Łukasz Pach ${ }^{1}$, Waldemar Kraska ${ }^{5}$ \\ ${ }^{1}$ Faculty of Medicine, the University of Technology in Katowice, Katowice, Poland \\ ${ }^{2}$ Department of Emergency Medical Service, Strategic Planning University of Dabrowa Gornicza, Dabrowa Gornicza, Poland \\ 3Department of Emergency Medicine, Medical University of Bialystok, Bialystok, Poland \\ ${ }^{4}$ Department of Emergency Medical Service, Medical University of Warsaw, Warsaw, Poland \\ ${ }^{5}$ Ministry of Health, Warsaw, Poland
}

\title{
The medical rescue system in Poland in the era of the SARS-CoV-2 pandemic
}

Key words: SARS-Cov-2, COVID-19, emergency medical team

\section{To the Editor:}

The SARS-CoV-2 pandemic was first identified in December 2019 in Wuhan, China. Since then, the virus has spread all over the world, including Poland [1, 2].

A very important aspect of the fight against coronavirus is the emergency medical system, which concerns pre-hospital care. As part of the State Medical Emergency System, in 2020 there were 1,585 medical rescue teams in Poland ( $73 \%$ were basic teams, without a doctor) and 21 air medical rescue teams.

In the period before the pandemic, emergency medical teams intervened approximately 3.4 million times each year. The most common life-threatening conditions are sudden cardiac arrest, chest pain, shortness of breath, injuries, traffic accidents, suspected stroke. The period of the ongoing pandemic changed the functioning of the emergency medical system.

Retrospective analysis of departure order cards and medical rescue cards from $15 / 03$ to $15 / 05$ in 2018-2020, showed a large decrease not only in interventions but also in individual disease symptoms. The data was prepare $d$ thanks to the Command Support System of the State Medical Rescue with the participation of the Ministry of Health. In 2018, 550,815 interventions of medical rescue teams were recorded, in 2019 - 527,837, but already in 2020 , during the SARS-CoV-2 pandemic, already 400,878 ( $p<0.001$ ). This is a drop in quantity by more than $20 \%$. Due to the reduced traffic on the roads, there was a decrease in traffic accidents by almost $50 \%$ and injuries by over $30 \%$, and reasons for calling "fainting" by over $40 \%$. The call for chest pain decreased by more than $15 \%$, for breathing disorders (dyspnoea) by almost $20 \%$. Only the call to suspect a stroke in the analysed period is at a similar level. The interventions for sudden cardiac arrest increased (by 5-10\%) [3].

We read the article by Gąsior et al. [4] with great interest. Where the analysis occurred of the medical rescue system data concerned departure order cards and emergency medical cards in the period from $11 / 03$ to $26 / 04$ in the years $2019-2020$. In the analysed voivodeships, by April 26, 2020, 2,599 infections were found - the most in the Śląskie Voivodeship - 1,867 people, in the Opolskie and Podlaskie voivodeships 363 and 369 infections, respectively. In all voivodeships, a decrease in the number of calls of emergency medical teams due to chest pain was observed, by an average of $8.3 \%$. The number of diagnoses of a heart attack made by the head of the emergency medical team decreased by $22.3 \%$. The number of hospitalizations due to myocardial infarction decreased by an average of $43.6 \%$.

The occurrence of the common causes of intervention by emergency medical teams, e.g., chest pain, injuries, fainting, suspected myocardial infarction significantly decreases in the COVID-19 era and similar trends were observed in Poland and other countries $[5,6]$. 


\section{Conflict of interest: None declared.}

\section{References}

1. Nowak B, Szymański P, Pańkowski I, et al. Clinical characteristics and short-term outcomes of patients with coronavirus disease 2019: a retrospective single-center experience of a designated hospital in Poland. Pol Arch Intern Med. 2020; 130(5): 407-411, doi: 10.20452/pamw.15361, indexed in Pubmed: 32420710

2. Wierzbik-Strońska M, Nadolny K, Grabarek B, et al. Characteristics of the intervention of emergency medical teams in the southern part of Poland in 12-month observation. Wiad Lek. 2020; 73(8): 1632-1636, doi: 10.36740/wlek202008108.
3. Kucap M, Nadolny K, Ładny JR, et al. Interventions of emergency medical teams in Poland during the SARS-CoV-2 pandemic. Kardiol Pol. 2021; 79(1): 72-75, doi: 10.33963/KP.15632, indexed in Pubmed: 33021351

4. Gasior M, Gierlotka M, Tycińska A, et al. Effects of the coronavirus disease 2019 pandemic on the number of hospitalizations for myocardial infarction: regional differences. Population analysis of 7 million people. Kardiol Pol. 2020; 78(10): 1039-1042, doi: 10.33963/KP.15559, indexed in Pubmed: 32820878

5. Nadolny K, Zyśko D, Obremska M, et al. Analysis of out-of-hospital cardiac arrest in Poland in a 1-year period: data from the POL-OHCA registry. Kardiol Pol. 2020; 78: 404-411.

6. De Rosa S, Spaccarotella C, Basso C, et al. Società Italiana di Cardiologia and the CCU Academy investigators group. Reduction of hospitalizations for myocardial infarction in Italy in the COVID-19 era. Eur Heart J. 2020; 41(22): 2083-2088, doi: 10.1093/eurheart//ehaa409, indexed in Pubmed: 32412631. 